\title{
Design and Simulation of Single Phase Shunt Active Filter using MATLAB
}

\author{
D C Bhonsle, Dr R B Kelkar
}

\begin{abstract}
Power Quality issues are becoming a major concern of today's power system engineers. Harmonics play significant roll in deteriorating power quality, called harmonic distortion. Harmonic distortion in electric distribution system is increasingly growing due to the widespread use of nonlinear loads. Large considerations of these loads have the potential to raise harmonic voltage and currents in an electrical distribution system to unacceptable high levels that can adversely affect the system. IEEE standards have defined limits for harmonic voltages and harmonic currents. Active power filters have been considered a potential candidate to bring these harmonic distortions within the IEEE limits. This paper deals with an active power filter (APF) based on simple control. A voltage source inverter with pulse width modulation (PWM) is employed to form the APF. A diode rectifier feeding capacitive-resistive load is considered as nonlinear load on ac mains for the elimination of harmonics by the proposed APF. MATLAB model of the scheme is simulated and obtained results are studied.
\end{abstract}

Index Terms-- Power Quality, THD, Non-linear Load, PWM

\section{INTRODUCTION}

$\mathrm{S}$ Olid state controllers are widely used to convert and control ac power to variety of loads to increase system efficiency and controllability. These converters draw nonsinusoidal current waveforms when supplied by a sinusoidal voltage source generating harmonics. Harmonic current propagation in electric power system results in distorted voltages and currents that can adversely affect the system performance in so many ways. Some of the undesirable effects in system performance are increased neutral currents in fourwire system, over heating of system components, mechanical oscillations in generators and motors, capacitor and insulation failure due to harmonic resonance, unpredictable behavior of installed protection systems, over heating of transformers and telephone interference [1-2].

Various types of tuned passive filters are used to limit a particular order of harmonic. The application of passive tuned filters creates new system resonances, which are dependent on specific system conditions. In addition, passive filters often

D. C. Bhonsle, research scholar, corresponding author, is with the Department of Electrical Enginering, C. K. Pithawalla College of Engg. \& Tech., $\mathrm{Nr}$ Malvan Mandir, Dumas Road, Surat, Gujarat. (E-mail: dcb191020@yahoo.co.in).

Dr. R. B. Kelkar, Professor with the Department of Electrical Engg., M. S. University of Baroda, Vadodara, Gujarat. need to be overrated to account for possible harmonic absorption from the power system [9-11].

Hence increased severity of harmonic pollution problem attracted the attention of power electronics experts in last one decade and large number of publications have appeared [6-8] on the development of an equipment named as Active Power Filter (APF) to provide a dynamic adjustable solution to eliminate harmonics in ac mains. Major attempts are made on 3-phase active filters considering the bulk power conversion. But there are large numbers of single phase loads in industrial and domestic sectors employing solid state control thus requiring the attention to the problem of harmonic pollution [1]. This paper is aimed to propose single phase active filter with simple control scheme to mitigate harmonics to a considerable limit.

\section{BASIC PRINCIPLE}

Fig. 1 shows function of single phase active power filter compensation principle, which is controlled in a closed loop manner to actively shape the source current into sinusoidal.

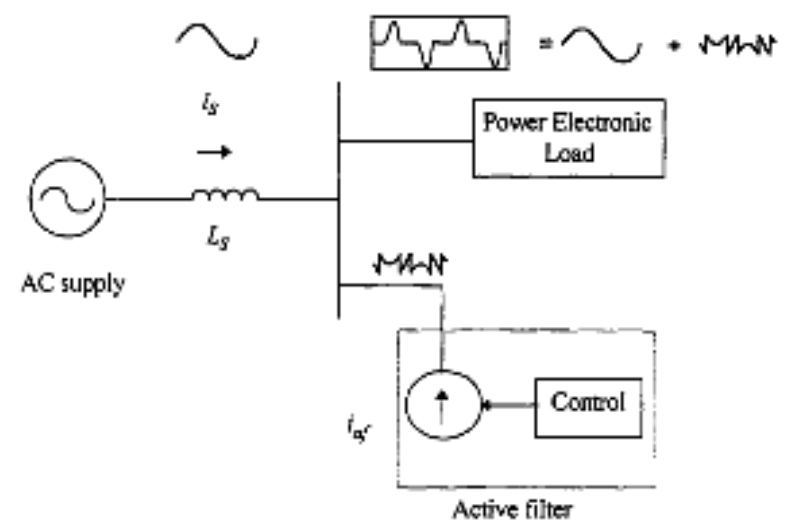

Fig. 1 Principle of Shunt connected SPAPF Single phase active filter concept uses power electronics to produce harmonic current components with $180^{\circ}$ phase shift to the harmonic current components generated from non-linear loads.

The shunt connected single phase active power filter is based on the principle of injection of harmonic currents into the ac 
system of the same amplitude but opposite in phase to that of the load harmonic currents.

The operation of the SPAPF, shown in Fig. 1, is investigated for the general case. It is assumed that the supply feeds single phase non-linear load, connected between the line and neutral. Also the current drawn by the load is non-sinusoidal and have all odd harmonics.

The load current is expressed as:

$$
i=i_{1}+i_{h}
$$

Where, $i_{1}$ is the fundamental component of the load current and $i_{h}$ is the harmonic current.

Now active filter current is given by:

$$
i_{\text {af }}=i_{h}
$$

Supply current is given by applying KCL at PCC:

$i_{s}=i-i_{\text {af }}$

Combining equations (1), (2) and (3):

$i_{s}=i_{1}$

Equation (4) theoretically shows that with SPAPF the supply current harmonics can be compensated completely.

\section{BASIC BLOCK DIAGRAM}

The utility is represented by an ideal ac voltage source in series with lumped impedance representing lines and transformers as shown in Fig. 3. SPAPF is consists of basic two components:

\subsection{Power electronic controller}

The voltage type inverter uses a capacitor with a regulated dc voltage. Compensation of harmonics can be accomplished in time-domain approach based upon 'on line'

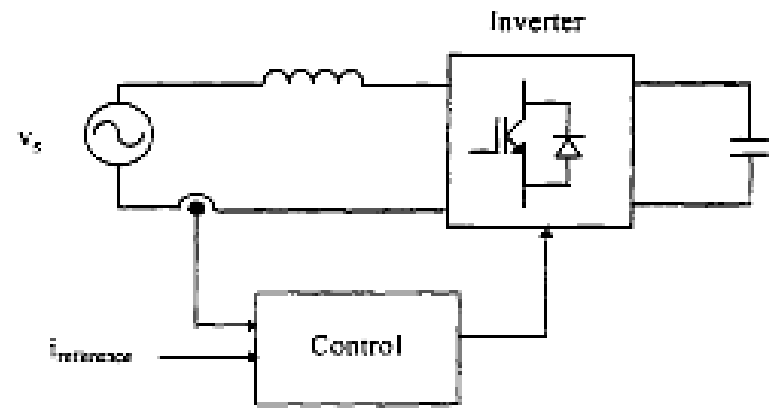

Fig. 3 Voltage fed inverter type Shunt APF

computation of an instantaneous error function.

\subsection{Controller}

This component is for determining the desired reference signal and generating the converter gating pulse.

\section{Design OverVIEW}

The detailed block diagram in Fig. 4 displays the proposed circuit.

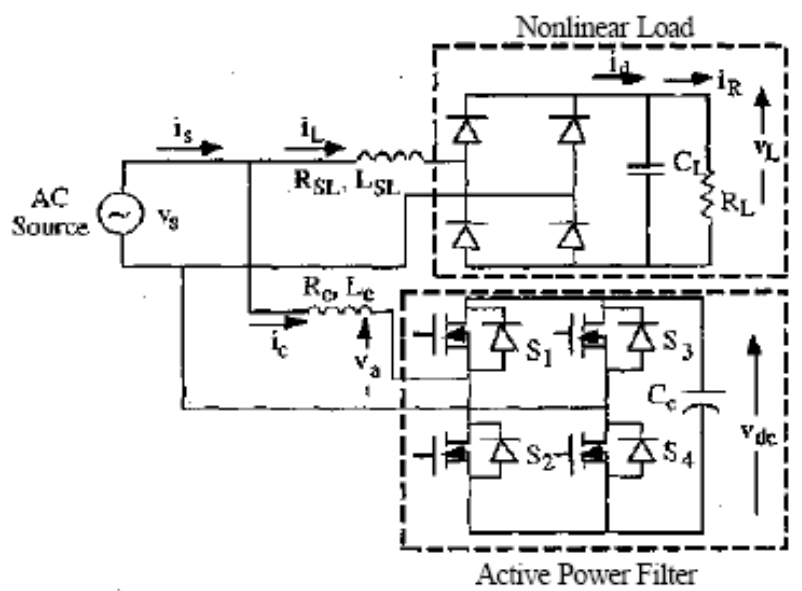

Fig. 4 Basic Circuit of Single Phase APF

Fig. 4 shows the basic circuit of APF including inverter having an energy storage capacitor on dc side. Pulse width modulation (PWM) is employed to generate gating pulses to the switches of APF. The dc based load fed from diode bridge rectifier with a capacitor is a non-linear load on the ac mains. The proposed APF is to eliminate harmonics and to improve the power factor of supply. The major parts constituting APF are described in brief:

\subsection{Voltage fed inverter}

A single phase voltage source IGBT bridge with an energy storage capacitor on dc side, connected in parallel with the load-thus forming a voltage fed inverter. The full bridge inverter is built by four IGBTs that chosen according to their suitable ratings. Anti-parallel diodes are connected across these power switches in term of protection and providing power conversion in reverse direction in order to recharge the dc capacitor whenever its level goes lower than a reference value. Large size capacitor is connected to the inverter such that constant level of voltage could be maintained over each switching cycle.

\subsection{Interface Filter}

The filter provides smoothing and isolation for high frequency components. Control of the injected current wave shape is limited by the switching frequency of the inverter and the available driving voltage across the interfacing inductance. The driving voltage across the interfacing inductance determines the maximum $\mathrm{di} / \mathrm{dt}$ that can be achieved by the filter. This is important because high values of di/dt may be needed to cancel higher order harmonic components. A large value of interfacing inductance is better for isolation but it 
limits the ability of an active filter to cancel higher order harmonics.

\subsection{PWM Controller}

A simplified P-I (Proportional-Integral) control of the dc capacitor average voltage is used to generate reference source current in phase with ac source voltage to result in unity power factor of the source current. The pulse width modulation (PWM) is employed to generate gating signal for IGBTs to control the phase and magnitude of the inverter output. PWM is chosen as a controller in this work due to its ability to reduce the distortion factor and lower order of harmonics as well besides that the phase and the magnitude of the fullbridge inverter can be easily changed.

\subsection{Non-linear load}

In this paper typical diode rectifier with capacitor-resistive load is taken as non-linear load on the ac main for simulation as shown in Fig. 4.

\section{PRoposed CONTROL SCHEME}

As shown in Fig. 5, the sensed dc voltage of the APF is compared with its set reference value in the error detector. The voltage error is processed in the P-I voltage controller. Its output is limited to the maximum permitted value. This output of the voltage controller is taken as peak value of supply current.

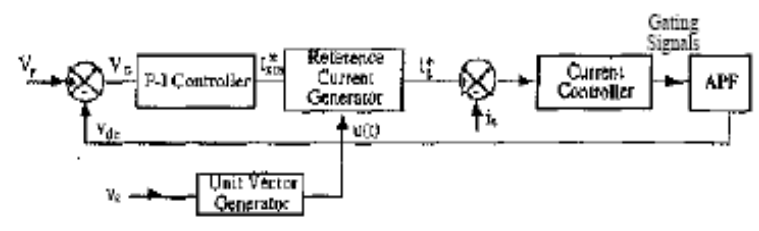

Fig. 5 Control Loop

The unit vector in phase with supply voltage is achieved using sensed source ac voltage. The output of the P-I controller is multiplied to unit vector to generate reference sinusoidal supply current in phase with supply voltage for the unit power factor of the ac source. This reference supply current is compared with sensed source current. A PWM is used over this current error to generate gating signal for the devices of the APF. The APF, in response to these gating pulses, generates a PWM voltage at the ac side of the APF. The impressed PWM voltage causes a current to flow through the inductor for the compensation of harmonics and reactive power of the load resulting in a unity PF.

\section{OPERATIOIN OF CONTROL LOOP}

Being connected to the PCC (Point of Common Coupling), during non-switching operation, APF charges dc capacitor via diodes to the maximum value of system voltage. Voltage of the $\mathrm{dc}$ capacitor experiences the second harmonic ripple of the ac mains fundamental frequency. Thus dc storage capacitor voltage is symmetric about half the period of the ac cycle under steady state operating condition. This voltage is averaged over the half cycle of ac mains for the use in P-I voltage controller. This P-I voltage controller will try to maintain constant dc capacitor voltage to a reference value. For that, it will draw the necessary power from ac source to meet the losses in the APF such as switching loss, capacitor leakage current, etc. in addition to the real power the load.

Under any disturbance in the load (either increase or decrease), the load will try to draw new increased or decreased value of current. This increased load current will be supplied immediately from the APF resulting in decreased energy storage on dc capacitor. It reduces the average voltage across dc capacitor. This reduction in dc capacitor voltage of the APF will activate the P-I controller and increases the supply current. This increased source current tries to restore the stored energy of the capacitor in addition to increased load active power. Supply current settles to new steady state value within few cycles. Vice-versa operation will be performed for load current decrease.

Since the corrective action of the P-I voltage controller is taken within the half cycle of the ac mains it results in fast response.

\section{SimUlation}

Non-linear load and Single phase active power filter are simulated using MATLAB/Simulink/SimPowerSystems [15]. Simulated MATLAB model is shown in Fig. 6 and Fig. 7.

\subsection{Non-linear load Simulation}

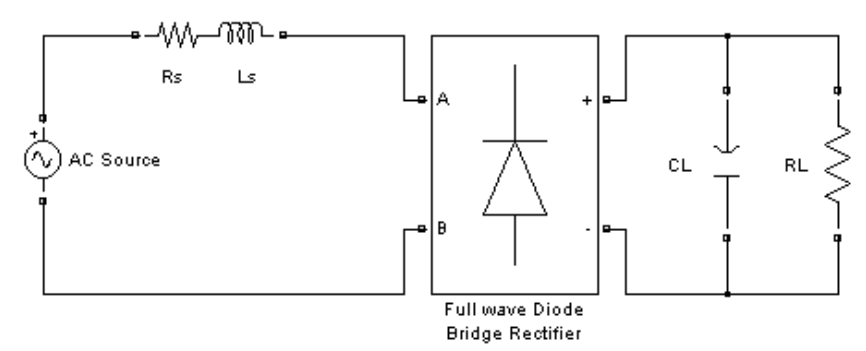

Fig. 6 MATLAB Simulation of Non-linear Load

\subsection{SPAPF Simulation}




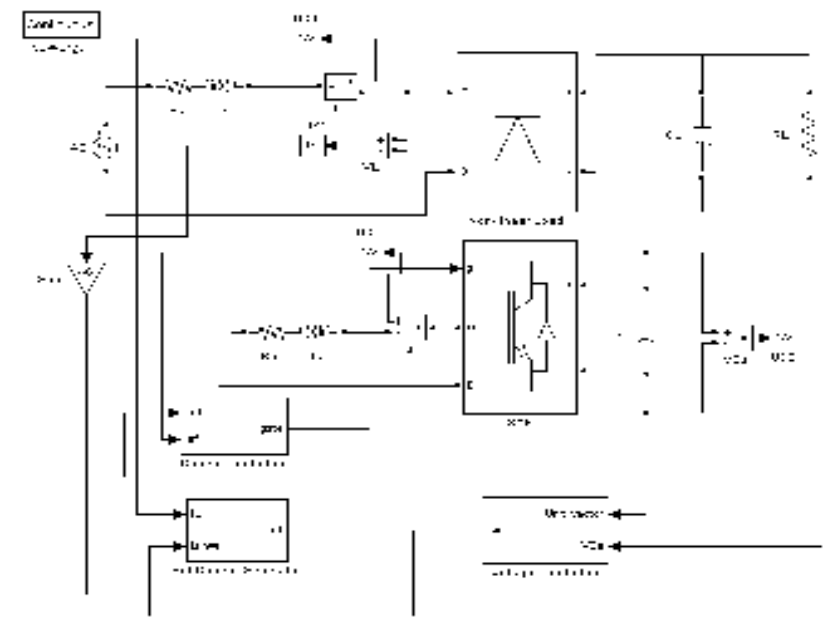

Fig. 7 MATLAB Simulation of SPAPF

\section{Simulation Results}

A standard FFT package is used to compute harmonic spectrum and THD of source current and source voltage for the following conditions.

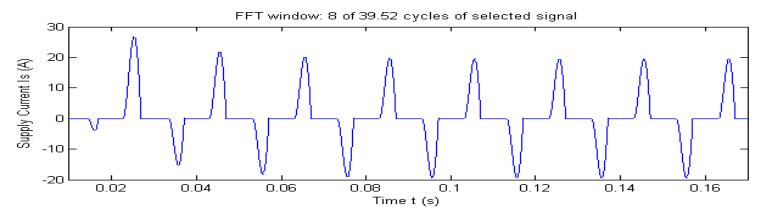

Fig. 8 Load Current without SPAPF

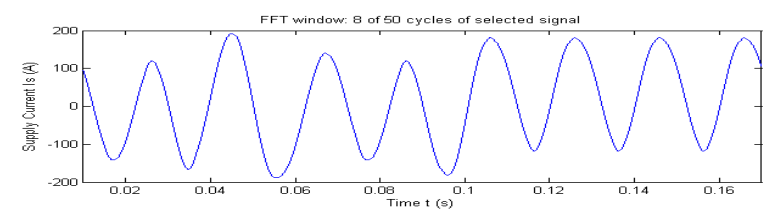

Fig. 9 Load Current with SPAPF

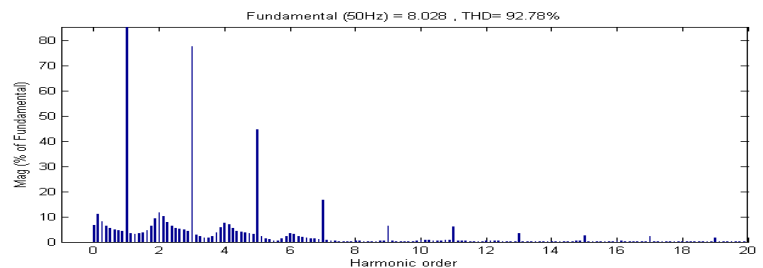

Fig. 10 Load Current Harmonic Spectrum without SPAPF

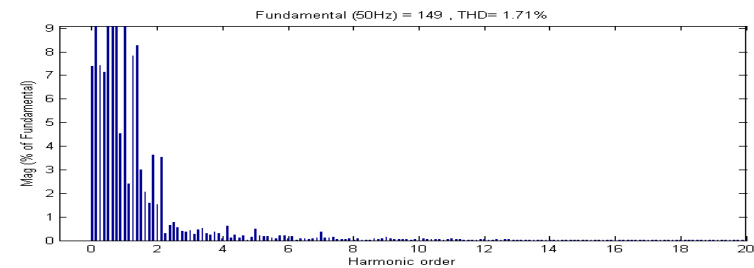

Fig. 10 Load Current Harmonic Spectrum with SPAPF
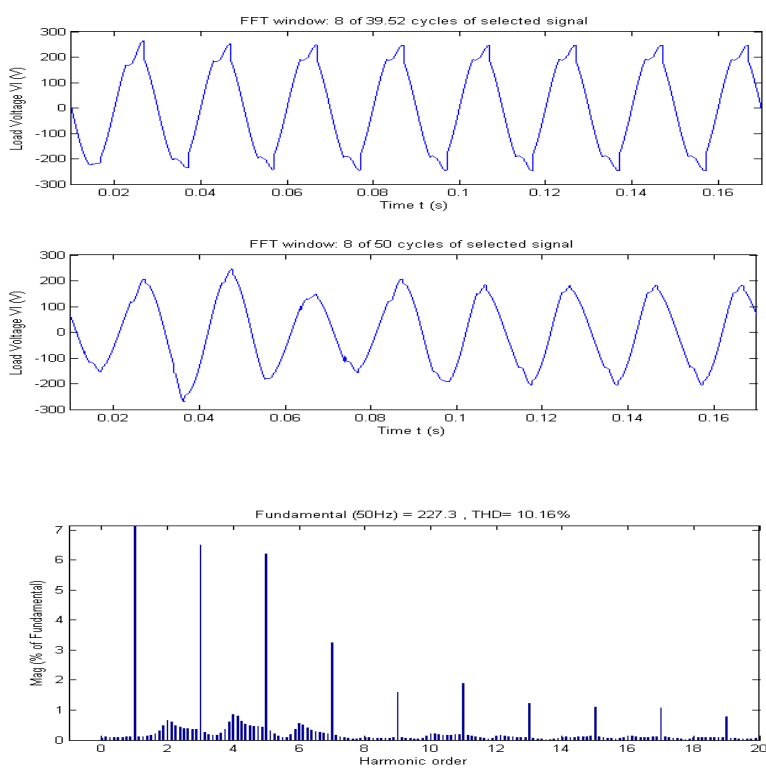

IX. SUMMARIES

\begin{tabular}{|l|l|l|l|}
\hline Parameter & $\begin{array}{l}\text { Without } \\
\text { APF }\end{array}$ & $\begin{array}{l}\text { With } \\
\text { APF }\end{array}$ & $\begin{array}{l}\text { \% } \\
\text { Reduction }\end{array}$ \\
\hline THD \% & 92.78 & 1.71 & $\mathbf{9 8 . 5 1}$ \\
\hline $3^{\text {rd }}$ Har \% & 77.65 & 0.41 & $\mathbf{9 9 . 4 7}$ \\
\hline $5^{\text {th }}$ Har \% & 44.65 & 0.48 & $\mathbf{9 8 . 9 2}$ \\
\hline $7^{\text {th }}$ Har \% & 16.64 & 0.36 & $\mathbf{9 7 . 8 3}$ \\
\hline $9^{\text {th }}$ Har \% & 6.34 & 0.13 & $\mathbf{9 7 . 9 4}$ \\
\hline $11^{\text {th }}$ Har \% & 6.18 & 0.07 & $\mathbf{9 8 . 8 6}$ \\
\hline
\end{tabular}

\begin{tabular}{|l|l|l|l|}
\hline Parameter & $\begin{array}{l}\text { Without } \\
\text { APF }\end{array}$ & $\begin{array}{l}\text { With } \\
\text { APF }\end{array}$ & $\begin{array}{l}\text { \% } \\
\text { Reduction }\end{array}$ \\
\hline THD \% & 10.16 & 3.39 & $\mathbf{6 6 . 6 3}$ \\
\hline $3^{\text {rd }}$ Har \% & 6.5 & 0.89 & $\mathbf{8 6 . 3}$ \\
\hline $5^{\text {th }}$ Har \% & 6.21 & 1.6 & $\mathbf{7 4 . 2 3}$ \\
\hline $7^{\text {th }}$ Har \% & 3.23 & 1.55 & $\mathbf{5 2}$ \\
\hline $9^{\text {th }}$ Har \% & 1.58 & 0.91 & $\mathbf{4 2 . 4}$ \\
\hline $11^{\text {th }}$ Har \% & 1.89 & 0.34 & $\mathbf{8 2}$ \\
\hline
\end{tabular}




\section{CONCLUSIONS}

1. THD as harmonic distortion index is defined.

2. Harmonic survey for various types of typical non-linear loads is done for both, industrial as well as domestic type of loads.

3. IEEE 519 limits for voltage and current harmonic distortion are studied.

4. $\mathrm{THD}_{\mathrm{V}}$ for the loads specified are ranging from 0.5 to 4.44 , which is within IEEE $\mathrm{THD}_{\mathrm{V}}$ limits.

5. $\mathrm{THD}_{\mathrm{I}}$ for the loads specified are ranging from 10 to 156.2 , which violates IEEE limits.

6. Harmonic mitigating methods should be employed to bring current harmonic distortion within the IEEE 519 standard limits. Passive tuned filters are one of the economical means of harmonic mitigation.

\section{REFERENCES}

\section{Periodicals}

[1] D. C. Bhonsle, Dr. R. B. Kelkar and N. K. Zaveri, "Power Quality Issues-In Distribution System”, IE(I) $23^{\text {rd }}$ National Convention of Electrical Engineers, Pune, November 2007 Proceedings, pp. 108-111.

[2] K. C. Umeh, A. Mohamed, R. Mohmed, " Comparing The Harmonic Characteristics of Typical Single Phase Nonlinear Loads", National Power Energy Conference (PECon) 2003 Proceedings, Bangi, Malaysia, pp. 383387.

[3] Mohamed S. A. Dahidah, N. Mariun, S. Mahmod and N. Khan, "Single Phase Active Power Filter for Harmonic Mitigation in Distribution Power Lines", National Power and Energy Conference (PECon) 2003 Proceedings, Bangi, Malaysia, pp. 359-362.

[4] Dalila Mat Said Ahmed, Abdullah asuhaimi, Mohd Zin, "Power Supply Quality Improvement: Harmonic Measurement and Simulation," National Power and Energy Conference (PECon), 2003 Proceedings, Bangi, Malaysia, pp. 352-358.

[5] C. Gopalkrishnan, K Udaykumar, T. A. Raghvendiran, "Survey of Harmonic Distortion for Power Quality Measurement and Application of Standard including Simulation," 2001, Anna University, India.

[6] L. A. Moran, J. W. Dixon, J. R. Espinoza, R. R. Wallace, "Using Active Power Filter to Improve Power Quality", Santiago, Chile, 2000.

[7] Joao L. Afonso, Mauricio Aredes, Edson Watanabe, Julio S. Martins, "Shunt Active Filter for Power Quality Improvement", International Conference UIE, Lisboa, Portugal, November 2000, pp. 683-691

[8] B. Singh, K. Al-Haddad and A. Chandra, "A Review of Active Filter for Power Quality Improvements", IEEE Trans. On Industrial Electronics, February 1999, pp. 960971.

\section{Books}

[9] J. Arrillaga, D. A. Bradley, P. S. Bodger, "Power System Harmonics”, New York: Wiley, 1985.

[10]E. Acha, M. Madrigal, "Power System Harmonics", Computer Modeling and Analysis, New York: Wiley, 2001.

\section{Technical Reports}

[11] M. S. Lalli, I. P. S. Paul, “ Field Measurement of Power Quality in Steel Rolling Mills", Centerl Power Research Institute (CPRI), Banglore. Pp. 279-282.

[12]Fluke Corporation, "Common Power Quality Factors affecting Transformers”, An Application Note, 2002.

[13] Marty Martin, P. E., "Two Modern Power Quality IssuesHarmonics and Grounding”, an Article.

\section{Standards}

[14]IEEE Recommended Practices and Requirements for Harmonic Control of Electrical Power Systems, IEEE Standards, 519, 1992, 1993.

\section{Software}

[15] Using MATLAB, Version 7.2, The Math Works, 2006. 